\title{
What has imaging contributed to the epidemiological understanding of osteoarthritis?
}

\author{
Pia M. Jungmann • Felix Liu • Thomas M. Link
}

Received: 18 July 2013 /Revised: 28 October 2013 / Accepted: 10 November 2013 / Published online: 18 December 2013

(C) ISS 2013

\section{Osteoarthritis}

Osteoarthritis (OA) is a leading cause of disability among the elderly. Knees and hips are most commonly affected; OA also occurs in the hands, shoulders, spine, and other joints. Symptomatic OA is defined by the American College of Rheumatology as a heterogeneous group of conditions that lead to joint symptoms and signs, which are associated with the defective integrity of articular cartilage, in addition to related changes in the underlying bone at the joint margins $[1,2]$. OA is differentiated into primary (idiopathic) and secondary (caused by a known medical condition or event) [1]. Clinical symptoms (pain, stiffness, and limited function) and radiographic features are frequently discrepant, particularly in the knee [3], shoulder [4], hand [5], and hip joint [6]. Most studies define OA status and outcome with imaging findings only [7, 8]. The goal of this review is to explore the contributions of imaging to the epidemiological understanding of OA, given the recent advancement in imaging technologies.

P. M. Jungmann • T. M. Link

Musculoskeletal and Quantitative Imaging Research, Department of Radiology and Biomedical Imaging, University of California San Francisco, 185 Berry Street, Suite 350,

San Francisco, CA 94107, USA

F. Liu

Department of Epidemiology and Biostatistics, University of California San Francisco, 185 Berry Street, Suite 5700,

San Francisco, CA 94107, USA

P. M. Jungmann $(\bowtie)$

Department of Radiology, Technical University of Munich, Ismaninger Strasse 22, 81675 Munich, Germany

e-mail: pia.jungmann@tum.de

\section{Large cohort studies}

There are several longitudinal cohort OA studies that include extensive imaging data. Most focus on the knees and/or hips. A few of the largest studies (in terms of imaging data) are the OA Initiative (OAI) (http://oai.epi-ucsf.org) [9], the Framingham OA Study [10-12], the Multicenter OA Study (MOST; http://most.ucsf.edu/), and the Boston Osteoarthritis of the Knee Study (BOKS; [13]). The Osteoporotic Fractures in Men Study (MrOS; [14]) and the Study of Osteoporotic Fractures for Women (SOF; http://sof.ucsf.edu/) both analyzed measures of OA as secondary aims. Other studies include the Beijing [15], NHANES [16], COPCORD [17], Wuchuan [18], and the ESORDIG [19] OA studies.

\section{Imaging techniques}

Conventional radiography is the current gold standard for OA diagnosis. It is commonly assessed using semi-quantitative scoring systems such as the Kellgren and Lawrence $(\mathrm{K} / \mathrm{L})$, Croft, and OARSI classifications. These systems grade joint space narrowing, osteophytes, and other radiographic features. Other radiographic techniques measure risk factors such as knee alignment or hip femoro-acetabular impingement. Novel quantitative approaches (trabecular structure, shape modeling, fractal signature analysis) aim to complement gold standard techniques to better detect or monitor disease using new software tools.

Ultrasound and scintigraphy have only limited application in OA. MRI provides most detailed information on presymptomatic and pre-radiographic changes and other associated joint pathologies [20]. These MRI findings are associated with onset of knee symptoms, OA progression, and total knee 
arthroplasty [21]. Therefore, the OA Research Society International (OARSI) recommended complementary MRI in clinical trials [22]. MR sequences, which have been used for clinical imaging and in clinical trials include intermediateweighted (IW) 2D fast spin-echo (FSE) sequences, 3D dualecho in steady state (DESS) sequences with selective water excitation (WE), and 3D T1-weighted fast low-angle shot (FLASH) sequences. Studies have reported benefits from contrast-enhanced sequences for evaluating synovitis (MOST) [23]. Other advanced sequences can suppress artifacts from foreign bodies or from motion. Recent increases in magnetic field strength have also improved image quality. Imaging with 3.0-T scanners provides substantial gain in signal and spatial resolution compared with 1.5-T whole-body and 1.0-T extremity scanners. Possible improvements from 7.0-T scanners are currently being explored. Semi-quantitative Whole Organ Magnetic Resonance Imaging Score (WORMS) is a reliable, specific and sensitive score for morphological analysis of the knee [13]. Alternative semi-quantitative analysis scores include the Knee Osteoarthritis Scoring System (KOSS; [24]), the BostonLeeds Osteoarthritis Knee Score (BLOKS; [25]), and the MRI Osteoarthritis Knee Score (MOAKS; [26]). The various scores do not complement one another and cross-study comparisons are problematic. Semi-quantitative assessment is also complex, which limits the exact assessment of disease burden and progression. Quantitative scores were therefore developed; the cartilage lesion (CAL) score uses measurements of cartilage lesions in three dimensions (OAI; Radiology 2013, in press), and other techniques focus on the quantification of cartilage matrix quality with special sequences (see below). These new sequences may detect degenerative changes earlier, observe progression within shorter time intervals and may also be helpful for outcome analyses post-surgery (such as cartilage repair or ligament reconstruction), but they are technically challenging and require specialized, time-consuming analysis algorithms.

\section{Structural changes in $\mathrm{OA}$ and clinical significance}

Assessment of OA is largely the evaluation of joint structures, particularly the articular cartilage, meniscus, bone marrow lesions (BML), ligaments, synovia, effusion, and cysts. Morphological knee cartilage lesions detected on MRI are associated with clinical symptoms, but reported correlations are inconsistent [27]. Cartilage thickness, volume, and surface are also used as outcome parameters given recent improvements in segmentation, analysis techniques, and atlases. Some studies include biochemical intrasubstance cartilage parameters: $T_{2}$ relaxation time sequences, $T_{1 \rho}$ relaxation time measurements, delayed gadolinium-enhanced MRI (dGEMRIC) [28], diffusion imaging, magnetization transfer analysis, and sodium MRI [29]. High and heterogeneous (texture analysis)
$\mathrm{T}_{2}$ values correlate with - and precede-morphological degeneration and clinical symptoms [30].

The meniscus is involved in symptom genesis and is a major risk factor for other structural changes once abnormal or resected (OAI) [31]; therefore, meniscus abnormality is used as an outcome measure (MOST). Incidental meniscal findings (tears, extrusion, cysts, etc.) are common and increase with age and $\mathrm{K} / \mathrm{L}$ grade (Framingham). Recently improved quantitative analysis techniques include meniscal shape, volume, position, MR signal intensity, $\mathrm{T}_{1 \rho}$, and $\mathrm{T}_{2}$ relaxation.

Pathological conditions of the anterior cruciate ligament (ACL), posterior cruciate ligament, collaterals, and other ligaments are significant risk factors. The incidence of ACL tears in OA patients is especially high; interestingly, tears do not influence short-term knee pain or function [32]. Even after ACL reconstruction, patients often suffer from continuing degeneration of the knee owing to rotational instability (which can be evaluated with kinematic MRI under loading) [33].

Similar to cartilage, subchondral bone marrow assessment shows abnormalities, which can be quantified. Subchondral bone marrow changes (bone marrow edema pattern/bone marrow lesions (BMLs) and cysts) are often assessed. Among all the joint abnormalities described, BMLs are associated most closely with clinical symptoms, disease progression, and joint replacement incidence; BMLs also have the ability to naturally decrease ([34, 35]; Tasmanian; Framingham; MOST). In addition, bone shape, surface area, denuded area, deformity, trabecular architecture (osteoporotic bone and bone mineral density) measures have been developed to better characterize OA (MrOS; SOF; OAI).

Lastly, joint effusion and synovitis may be associated with symptomatic OA and pain (OAI, MOST, BOKS). A synovitis scoring system to identify painful knees was proposed in contrast-enhanced MRI, but synovial analysis techniques are lacking (MOST).

Independent associations of these structures with OA suggest that clinical OA symptoms might be multifactorial. Many pathological structures are OA risk factors, but concurrently define radiographic OA status. Certain combinations of structural pathological conditions may possibly better characterize $\mathrm{OA}$ risk and progression.

\section{Other risk factors}

Some major risk factors are non-modifiable, but strongly correlated. Women are at a higher risk of knee, but not hip OA. The distribution of locations within affected joints also differs by sex. Age is an important non-modifiable risk factor. Post-traumatic deformities, congenital abnormalities, and biomechanical abnormalities may contribute to early OA. Greater knee height, causing greater moment arms and mechanical 
forces around the knee, and patellar malalignment also increase risk (Beijing; BOKS; MOST). For assessing varus or valgus malalignment, which results in compartment-specific OA, the gold standard is full limb radiography, although recently it has been shown that alignment can also be estimated from standing knee X-rays. New techniques of subjectspecific biomechanical modeling applying finite element analysis identified increased contact stress prior to the development of OA. Novel techniques focus on correcting the abnormal contact stresses, but currently lack convincing evidence.

Most modifiable factors are effective at reducing OA risk, but require patient contribution. Obesity or fat mass and high physical activity (repetitive joint overuse, knee bending, and squatting) are the main modifiable risk factors (Framingham; Chingford; HANES; Rotterdam; MOST; OAI; Wuchuan; Beijing) [36]. Muscle strength and volume, as measured by improved techniques, are associated with knee abnormalities (OAI; Beijing; MOST). Vitamin D and vitamin C serum levels correlate with OA findings (SOF; Framingham; BOKS). Although smoking slightly decreases OA risk, it increases longitudinal cartilage loss (Framingham) [36]. Lastly, alcohol consumption has no visible influence.

Genetic risk factors may involve genes such as COMP, collagen 2A1, vitamin D receptor genes, and N-telopeptide crosslinks may all play a role (Rotterdam; SOF; BOKS). Large cohort studies observe geographic trends, but the determinant factors (race, lifestyle, environment) are unknown. The prevalence of hip abnormalities, hip OA, and hand OA in China was lower than in the United States, but lateral knee OA prevalence in particular is higher (Beijing, Framingham).

\section{Prevalence}

Although imaging techniques and imaging-based treatment options have rapidly improved and are now more costeffective, the economic costs of $\mathrm{OA}$ are paradoxically rising. Lifetime risk of joint replacement has increased owing to increasing OA prevalence (NHANES; Framingham) [37-39]. Hardware and surgery improvements have widened the eligible age range for joint replacements [40]. However, it is dependent on socio-economic circumstances $[37,40]$. While the incidence of joint replacements can be assessed, the epidemiology of OA is harder to define and becomes increasingly complex with new, more sensitive imaging techniques. Plain radiographs still remain the gold standard [1], likely in part because of the complexity of novel imaging [41]. An MRI definition of OA has been described, but requires validation [41]. Asymptomatic subjects without radiographic OA frequently show signs of degenerative changes in morphological MRI [42]; quantitative measures are even predictive of morphological joint degeneration in cartilage, meniscus, and bone marrow (Framingham; OAI) $[43,44]$. Treatment of early changes may influence the epidemiology of advanced OA secondarily. But an exact definition of early OA is still lacking [45]. Currently, approximately $10 \%$ of the adult population in the USA have symptomatic OA [46]. In the Framingham cohort radiographic hand OA was found in about $40 \%$ of subjects aged $>40$ years [47], while radiographic knee OA was found in about $28 \%$ (16\% symptomatic) of subjects $>45$ years in the Johnston County Osteoarthritis Project [48]. Another study from the Johnston County Osteoarthritis Project reported that $28 \%$ of the population had radiographic hip OA (10\% symptomatic) [49]. Prevalence of mild to severe radiographic OA of the glenohumeral joint was found in about $5 \%$ of older Korean individuals [50].

\section{Conclusions}

Osteoarthritis research studies provide large imaging datasets that have contributed greatly to a better understanding of the epidemiology of degenerative joint disease, in particular in relation to:

1. The role of structural abnormalities, their interaction and evolution

2. Biomechanical, structural, systemic, genetic, nutritional, and geographic risk factors

3. Prediction of OA and longitudinal progression

4. Clinical symptoms and outcomes

New imaging techniques are able to better identify and monitor biochemical and quantitative degenerative changes in relation to structural risk factors. Early OA is still not sufficiently defined, but the discrepancy between imaging and clinical findings has been reduced. Rising economic costs underline the importance of further investigation and of implementing detection and risk reduction strategies. Apart from developing population-based strategies, imaging improvements potentially allow for early, even tissue-specific prevention, intervention, monitoring, and targeting of specific individual changes.

Conflict of interest None.

\section{References}

1. Altman R, Asch E, Bloch D, Bole G, Borenstein D, Brandt K, et al. Development of criteria for the classification and reporting of osteoarthritis. Classification of osteoarthritis of the knee. Diagnostic and Therapeutic Criteria Committee of the American Rheumatism Association. Arthritis Rheum. 1986;29(8):1039-49.

2. Guilbert JJ. The world health report 2002 - reducing risks, promoting healthy life. Educ Health (Abingdon). 2003;16(2):230. 
3. Bedson J, Croft PR. The discordance between clinical and radiographic knee osteoarthritis: a systematic search and summary of the literature. BMC Musculoskelet Disord. 2008;9:116.

4. Kircher J, Morhard M, Magosch P, Ebinger N, Lichtenberg S, Habermeyer P. How much are radiological parameters related to clinical symptoms and function in osteoarthritis of the shoulder? Int Orthop. 2010;34(5):677-81.

5. Hart DJ, Spector TD, Brown P, Wilson P, Doyle DV, Silman AJ. Clinical signs of early osteoarthritis: reproducibility and relation to $\mathrm{x}$ ray changes in 541 women in the general population. Ann Rheum Dis. 1991;50(7):467-70.

6. Odding E, Valkenburg HA, Algra D, Vandenouweland FA, Grobbee DE, Hofman A. Associations of radiological osteoarthritis of the hip and knee with locomotor disability in the Rotterdam Study. Ann Rheum Dis. 1998;57(4):203-8.

7. Hunter DJ. Imaging insights on the epidemiology and pathophysiology of osteoarthritis. Rheum Dis Clin N Am. 2009;35(3):447-63.

8. Pereira D, Peleteiro B, Araujo J, Branco J, Santos RA, Ramos E. The effect of osteoarthritis definition on prevalence and incidence estimates: a systematic review. Osteoarthritis Cartilage. 2011;19(11): 1270-85.

9. Eckstein F, Wirth W, Nevitt MC. Recent advances in osteoarthritis imaging-the osteoarthritis initiative. Nat Rev Rheumatol. 2012;8(10):622-30.

10. Felson DT, Anderson JJ, Naimark A, Walker AM, Meenan RF, Obesity and knee osteoarthritis. The Framingham Study. Ann Intern Med. 1988;109(1):18-24.

11. Oliveria SA, Felson DT, Reed JI, Cirillo PA, Walker AM. Incidence of symptomatic hand, hip, and knee osteoarthritis among patients in a health maintenance organization. Arthritis Rheum. 1995;38(8):1134-41.

12. Hunter DJ, Niu JB, Zhang Y, LaValley M, McLennan CE, Hudelmaier $\mathrm{M}$, et al. Premorbid knee osteoarthritis is not characterised by diffuse thinness: the Framingham Osteoarthritis Study. Ann Rheum Dis. 2008;67(11):1545-9.

13. Hunter DJ, Zhang Y, Niu J, Tu X, Amin S, Goggins J, et al. Structural factors associated with malalignment in knee osteoarthritis: the Boston osteoarthritis knee study. J Rheumatol. 2005;32(11):2192-9.

14. Blank JB, Cawthon PM, Carrion-Petersen ML, Harper L, Johnson JP, Mitson E, et al. Overview of recruitment for the osteoporotic fractures in men study (MrOS). Contemp Clin Trials. 2005;26(5):557-68.

15. Zhang $\mathrm{Y}, \mathrm{Xu} \mathrm{L}$, Nevitt MC, Aliabadi $\mathrm{P}, \mathrm{Yu} \mathrm{W}$, Qin $\mathrm{M}$, et al. Comparison of the prevalence of knee osteoarthritis between the elderly Chinese population in Beijing and whites in the United States: The Beijing Osteoarthritis Study. Arthritis Rheum. 2001;44(9):2065-71.

16. Dillon CF, Rasch EK, Gu Q, Hirsch R. Prevalence of knee osteoarthritis in the United States: arthritis data from the Third National Health and Nutrition Examination Survey 1991-94. J Rheumatol. 2006;33(11):2271-9.

17. Haq SA, Davatchi F. Osteoarthritis of the knees in the COPCORD world. Int J Rheum Dis. 2011;14(2):122-9.

18. Kang X, Fransen M, Zhang Y, Li H, Ke Y, Lu M, et al. The high prevalence of knee osteoarthritis in a rural Chinese population: the Wuchuan osteoarthritis study. Arthritis Rheum. 2009;61(5):641-7.

19. Andrianakos A, Trontzas P, Christoyannis F, Dantis P, Voudouris C, Georgountzos A, et al. Prevalence of rheumatic diseases in Greece: a cross-sectional population based epidemiological study. The ESORDIG Study. J Rheumatol. 2003;30(7):1589-601.

20. Keen HI, Mease PJ, Bingham 3rd CO, Giles JT, Kaeley G, Conaghan PG. Systematic review of MRI, ultrasound, and scintigraphy as outcome measures for structural pathology in interventional therapeutic studies of knee arthritis: focus on responsiveness. J Rheumatol. 2011;38(1):142-54.

21. Hunter DJ, Zhang W, Conaghan PG, Hirko K, Menashe L, Li L, et al. Systematic review of the concurrent and predictive validity of MRI biomarkers in OA. Osteoarthritis Cartilage. 2011;19(5):557-88.
22. Conaghan PG, Hunter DJ, Maillefert JF, Reichmann WM, Losina E. Summary and recommendations of the OARSI FDA osteoarthritis Assessment of Structural Change Working Group. Osteoarthritis Cartilage. 2011;19(5):606-10.

23. Guermazi A, Roemer FW, Hayashi D, Crema MD, Niu J, Zhang Y, et al. Assessment of synovitis with contrast-enhanced MRI using a whole-joint semiquantitative scoring system in people with, or at high risk of, knee osteoarthritis: the MOST study. Ann Rheum Dis. 2011;70(5):805-11.

24. Kornaat PR, Ceulemans RY, Kroon HM, Riyazi N, Kloppenburg M, Carter WO, et al. MRI assessment of knee osteoarthritis: Knee Osteoarthritis Scoring System (KOSS)-inter-observer and intraobserver reproducibility of a compartment-based scoring system. Skelet Radiol. 2005;34(2):95-102.

25. Hunter DJ, Lo GH, Gale D, Grainger AJ, Guermazi A, Conaghan PG. The reliability of a new scoring system for knee osteoarthritis MRI and the validity of bone marrow lesion assessment: BLOKS (Boston Leeds Osteoarthritis Knee Score). Ann Rheum Dis. 2008;67(2):206-11.

26. Hunter DJ, Guermazi A, Lo GH, Grainger AJ, Conaghan PG, Boudreau RM, et al. Evolution of semi-quantitative whole joint assessment of knee OA: MOAKS (MRI Osteoarthritis Knee Score). Osteoarthritis Cartilage. 2011;19(8):990-1002.

27. Link TM, Steinbach LS, Ghosh S, Ries M, Lu Y, Lane N, et al. Osteoarthritis: MR imaging findings in different stages of disease and correlation with clinical findings. Radiology. 2003;226(2):373-81.

28. Bittersohl B, Miese FR, Dekkers C, Senyurt H, Kircher J, Wittsack $\mathrm{HJ}$, et al. T2* mapping and delayed gadolinium-enhanced magnetic resonance imaging in cartilage (dGEMRIC) of glenohumeral cartilage in asymptomatic volunteers at 3 T. Eur Radiol. 2013;23(5): 1367-74

29. Eckstein F, Burstein D, Link TM. Quantitative MRI of cartilage and bone: degenerative changes in osteoarthritis. NMR Biomed. 2006;19(7):822-54.

30. Urish KL, Keffalas MG, Durkin JR, Miller DJ, Chu CR, Mosher TJ. T2 texture index of cartilage can predict early symptomatic OA progression: data from the osteoarthritis initiative. Osteoarthritis Cartilage. 2013;21(10):1550-7.

31. Badlani JT, Borrero C, Golla S, Harner CD, Irrgang JJ. The effects of meniscus injury on the development of knee osteoarthritis: data from the osteoarthritis initiative. Am J Sports Med. 2013;41(6):1238-44.

32. Amin S, Guermazi A, Lavalley MP, Niu J, Clancy M, Hunter DJ, et al. Complete anterior cruciate ligament tear and the risk for cartilage loss and progression of symptoms in men and women with knee osteoarthritis. Osteoarthritis Cartilage. 2008;16(8):897-902.

33. Haughom B, Schairer W, Souza RB, Carpenter D, Ma CB, Li X. Abnormal tibiofemoral kinematics following ACL reconstruction are associated with early cartilage matrix degeneration measured by MRI T1rho. Knee. 2012;19(4):482-7.

34. Felson DT, Niu J, Guermazi A, Roemer F, Aliabadi P, Clancy M, et al. Correlation of the development of knee pain with enlarging bone marrow lesions on magnetic resonance imaging. Arthritis Rheum. 2007;56(9):2986-92.

35. Tanamas SK, Wluka AE, Pelletier JP, Pelletier JM, Abram F, Berry $\mathrm{PA}$, et al. Bone marrow lesions in people with knee osteoarthritis predict progression of disease and joint replacement: a longitudinal study. Rheumatology (Oxford). 2010;49(12):2413-9.

36. Felson DT, Zhang Y, Hannan MT, Naimark A, Weissman B, Aliabadi $\mathrm{P}$, et al. Risk factors for incident radiographic knee osteoarthritis in the elderly: the Framingham Study. Arthritis Rheum. 1997;40(4): 728-33.

37. Bohensky M, Ackerman I, De Steiger R, Gorelik A, Brand C. Lifetime risk of total knee replacement and temporal trends in incidence by health care setting, socioeconomic status and geographic location. Arthritis Care Res (Hoboken). 2013 10.1002/acr.22122. 
38. Hiligsmann M, Cooper C, Arden N, Boers M, Branco JC, Luisa Brandi M, et al. Health economics in the field of osteoarthritis: an expert's consensus paper from the European Society for Clinical and Economic Aspects of Osteoporosis and Osteoarthritis (ESCEO). Semin Arthritis Rheum. 2013 10.1016/j.semarthrit.2013.07.003.

39. Nho SJ, Kymes SM, Callaghan JJ, Felson DT. The burden of hip osteoarthritis in the United States: epidemiologic and economic considerations. J Am Acad Orthop Surg. 2013;21 Suppl 1:S1-6.

40. Mota RE, Tarricone R, Ciani O, Bridges JF, Drummond M. Determinants of demand for total hip and knee arthroplasty: a systematic literature review. BMC Health Serv Res. 2012;12:225.

41. Hunter DJ, Arden N, Conaghan PG, Eckstein F, Gold G, Grainger A, et al. Definition of osteoarthritis on MRI: results of a Delphi exercise. Osteoarthritis Cartilage. 2011;19(8):963-9.

42. Englund M, Guermazi A, Gale D, Hunter DJ, Aliabadi P, Clancy M, et al. Incidental meniscal findings on knee MRI in middle-aged and elderly persons. N Engl J Med. 2008;359(11):1108-15.

43. Guermazi A, Niu J, Hayashi D, Roemer FW, Englund M, Neogi T, et al. Prevalence of abnormalities in knees detected by MRI in adults without knee osteoarthritis: population based observational study (Framingham Osteoarthritis Study). BMJ. 2012;345:e5339.

44. Joseph GB, Baum T, Alizai H, Carballido-Gamio J, Nardo L, Virayavanich W, et al. Baseline mean and heterogeneity of MR cartilage T2 are associated with morphologic degeneration of cartilage, meniscus, and bone marrow over 3 years-data from the Osteoarthritis Initiative. Osteoarthritis Cartilage. 2012;20(7):727-35.

45. Luyten FP, Denti M, Filardo G, Kon E, Engebretsen L. Definition and classification of early osteoarthritis of the knee. Knee Surg Sports Traumatol Arthrosc. 2012;20(3):401-6.

46. Hunter DJ. Osteoarthritis. Best Pract Res Clin Rheumatol. 2011;25(6):801-14.

47. Haugen IK, Englund M, Aliabadi P, Niu J, Clancy M, Kvien TK, et al. Prevalence, incidence and progression of hand osteoarthritis in the general population: the Framingham Osteoarthritis Study. Ann Rheum Dis. 2011;70(9):1581-6.

48. Jordan JM, Helmick CG, Renner JB, Luta G, Dragomir AD, Woodard J, et al. Prevalence of knee symptoms and radiographic and symptomatic knee osteoarthritis in African Americans and Caucasians: the Johnston County Osteoarthritis Project. J Rheumatol. 2007;34(1):172-80.

49. Jordan JM, Helmick CG, Renner JB, Luta G, Dragomir AD, Woodard $\mathrm{J}$, et al. Prevalence of hip symptoms and radiographic and symptomatic hip osteoarthritis in African Americans and Caucasians: the Johnston County Osteoarthritis Project. J Rheumatol. 2009;36(4):809-15.

50. Oh JH, Chung SW, Oh CH, Kim SH, Park SJ, Kim KW, et al. The prevalence of shoulder osteoarthritis in the elderly Korean population: association with risk factors and function. J Shoulder Elbow Surg. 2011;20(5):756-63. 